\title{
Accuracy of Roughage Intake Estimations as Determined by A Chromic Oxide-In Vitro Digestibility Technique
}

R.E. ROSIERE, M.L. GALYEAN AND JOE D. WALLACE

\section{Abstract}

Intakes of roughage rations by two-year-old cows and heifers were estimated by a chromic oxide dilution technique and compared against actual measured levels of intake. Intake was overestimated 2.9 percent in cows and 28.6 percent in heifers. Linear regression was used to increase accuracy of intake estimates by developing equations to predict actual

The authors are with the Department of Forestry and Resource Management, University of California, Berkeley, 94720, and the Department of Animal and Range Sciences, New Mexico State University, Las Cruces, 88003.

This report is JournaI Article 694, Agr. Exp. Sta., New Mexico State University, Las Cruces.

Manuscript received November 20, 1978. intake from values obtained by the indicator dilution approach. A system for using this approach under range conditions was suggested. It was shown that non-adjusted intake estimates were not absolute values and the assumption that estimated intake values are relative and adequate for comparison is valid only when ruminants consume similar diets.

Forage intake in grazing ruminants is often estimated by the fecal output-indigestibility ratio technique. Production of feces can be determined by dosing animals with known amounts of inert markers and dividing this quantity by the concentration of marker in fecal samples. Chromic oxide (chromium sesquioxide, $\mathrm{Cr}_{2} \mathrm{O}_{3}$ ) is probably 
the most widely used external indicator for this purpose. Accuracy of these determinations is often questionable since $\mathrm{Cr}_{2} \mathrm{O}_{3}$ is excreted diurnally and may be incompletely recovered (Kiesling et al 1969). The following test was conducted to evaluate the ability of the chromic oxide approach to measure accurately roughage intake by cattle.

\section{Experimental Procedure}

Daily intakes of cottonseed hulls were measured during a 7-day trial in a group of three two-year-old cows ( 30 days postpartum) and in a group of four two-year-old heifers fitted with esophageal fistulae. Cows (426 kg avg. wt.) received $3.63 \mathrm{~kg}$ of alfalfa pellets per head daily and heifers (417 kg avg. wt.) received $1.36 \mathrm{~kg}$ to "balance" ad libitum rations of cottonseed hulls. New supplies of hulls were weighed and fed each morning at which time orts were weighed back. Consumption was determined for each $24 \mathrm{hr}$ period by difference.

Roughage intake was estimated for each day of the trial using the $\mathrm{Cr}_{2} \mathrm{O}_{3}$ marker technique. Chromic oxide was given in shredded, 36 percent $\mathrm{Cr}_{2} \mathrm{O}_{3}$-impregnated paper inside of gelatin capsules which were administered to cattle through esophageal fistulae. Two capsules, each of which contained $9 \mathrm{~g}$ shredded paper, were given at 0700 and 1700 hrs during the trial beginning five days prior to first sampling of feces and ending one day before last fecal sampling. Rectal grab samples were taken concomitantly with dosing starting 6 days after initiation of marker administration and ending one day before termination of the trial. Daily dosage of chromium sesquioxide was $12.9 \mathrm{~g}$.

Fecal samples from individual animals were composited by group, dried at $50^{\circ} \mathrm{C}$ and ground through a Wiley Mill (1 mm screen). Dry matter and ash were determined on feces and rations based on A.O.A.C. (1965) procedures. Concentration of $\mathrm{Cr}_{2} \mathrm{O}_{3}$ in feccs was determined by a colorimetric method adapted from Kimura and Miller (1957)

A series of $\mathrm{Cr}_{2} \mathrm{O}_{3}$ standards ranging in concentration from .6065 $\mathrm{mg} / \mathrm{ml}$ to $.2426 \mathrm{mg} / \mathrm{ml}(0.03033 \mathrm{mg} / \mathrm{ml}$ increments $)$ was established. Optical densities of standards and unknown fecal samples were determined with a Bausch and Lomb Spectronic 20 colorimeter. Fecal samples had been prepared by wet ashing with nitric acid followed by perchloric acid digestion (Kimura and Miller 1957). Simple linear regression was utilized to establish a relationship between the independent variable, optical density, and the dependent variable, $\mathrm{Cr}_{2} \mathrm{O}_{3}$ concentration. The regression equation derived from this process was as follows:

$Y=-0.00108+X(0.33007)$

where $Y=\mathrm{Cr}_{2} 0_{33}$ concentration $(\mathrm{mg} / \mathrm{ml})$.

Chromic oxide concentration in unknown samples was determined using the above equation. Multiplication by dilution factors and division by weight of sample organic matter yielded $\mathrm{Cr}_{2} \mathrm{O}_{3}$ concentration per $g$ organic matter in feces.

Percent indigestibility was determined as 100 percent minus digestion coefficient of the two rations which were estimated by the in vitro organic matter disappearance procedure of Tilley and Terry (1963). Intake was then calculated by dividing the daily dose of $\mathrm{Cr}_{2} \mathrm{O}_{3}$ by $\mathrm{Cr}_{2} \mathrm{O}_{3}$ conc. on an organic matter basis to provide an estimate of fecal excretion. Division of estimated fecal excretion by in vitro indigestibility yielded intake estimates.

\section{Results and Discussion}

The marker technique overestimated intakes of cottonseed hullpellet rations by 16 percent when averaged over days for both groups of cattle (2.9 percent for cows and 28.6 percent for heifers). However, cow estimates were more variable than those for heifers (Table 1). Testing by paired comparison showed that actual and estimated values differed from each other $(P<.05)$ in both cows and heifers. Percentage of variation accounted for in actual intake by regression on estimated intake was low ( $r=.42$ and .16 for cow and heifer data, respectively).

It is obvious that roughage intake could not be determined absolutely by this procedure. Several problems are inherent in the indirect technique. First the in vitro procedure does not allow for individual animal variation in digestibility which may result in an over or underestimation of actual intake. In a sense, chromic oxide may quite effectively estimate fecal output but poor estimates of digestibility might result in inferior estimates of intake. A second problem involves the technique for measurement of chromic oxide. Connor et al. (1963) included fecal ash in chromic oxide standards and indicated that a standard curve based solely on $\mathrm{Cr}_{2} \mathrm{O}_{3}$ would have overestimated fecal excretion by $14 \%$. Since fecal ash was not included in standards in the study reported herein, fecal excretion and thus intake may have been overestimated.

Accuracy of intake estimations could be improved by using adjustment approaches such as linear regression. Least squares formulae were developed for predicting actual roughage intake from estimated values of intake obtained by the $\mathrm{Cr}_{2} \mathrm{O}_{3}$ dilution technique. With days (Table 1) assumed to be independent observations, the following equations with $\mathrm{Cr}_{2} \mathrm{O}_{3}$ estimated intake as the independent variable were derived:

$$
\begin{aligned}
& Y_{1}=-0.35178 \mathrm{E}_{1}+17.75745 ; \text { Sy. } \mathrm{x}=1.2494, \mathrm{r}^{2}=.42 \\
& Y_{2}=0.10582 \mathrm{E}_{2}+6.88544 ; \text { Sy. } \mathrm{x}=.2766, \mathrm{r}^{2}=.16
\end{aligned}
$$
where

$Y_{1}=$ Actual roughage intake of cows

$Y_{2}=$ Actual roughage intake of heifers

$\mathrm{E}_{1}=$ Estimated intake of cows from $\mathrm{Cr}_{2} \mathrm{O}_{3}$ dilution

$\mathrm{E}_{2}=$ Estimated intake of heifers from $\mathrm{Cr}_{2} \mathrm{O}_{3}$ dilution

Table 1 shows the results of adjusting $\mathrm{Cr}_{2} \mathrm{O}_{3}$ estimated data using the regression equations given above. Overall mean intake predicted from regression was more similar to actual roughage intake than was the mean $\mathrm{Cr}_{2} \mathrm{O}_{3}$ estimation for both cows and heifers. The improvement in accuracy is especially evident among heifers (8.1 actual vs 8.1 predicted vs $11.3 \mathrm{Cr}_{2} \mathrm{O}_{3}$ estimated).

Readers should be cautioned that the above procedure is merely an example of how estimated intake data could be corrected by regression techniques. A more appropriate experimental procedure would involve the derivation of estimated and actual intakes for individual

Table 1. Comparison between actual and estimated ${ }^{a}$ organic matter intake of cottonseed hull-alfalfa pellet ${ }^{b}$ rations by two-year-old primiparous cows and

\begin{tabular}{|c|c|c|c|c|c|c|}
\hline \multirow[b]{2}{*}{ Day } & \multicolumn{3}{|c|}{ Cows } & \multicolumn{3}{|c|}{ Heifers } \\
\hline & Actual & Estimated & $\begin{array}{c}\text { Predicted } \\
\text { From Regression }\end{array}$ & Actual & Estimated & $\begin{array}{c}\text { Predicted } \\
\text { From Regression }\end{array}$ \\
\hline 1 & 12.4 & 16.7 & 11.9 & 7.9 & 10.4 & 8.0 \\
\hline 2 & 12.4 & 12.5 & 13.4 & 7.7 & 10.4 & 8.0 \\
\hline 3 & 13.2 & 11.9 & 13.6 & 7.9 & 11.8 & 8.1 \\
\hline 4 & 15.2 & 11.9 & 13.6 & 8.5 & 10.7 & 8.0 \\
\hline 5 & 11.7 & 16.1 & 12.1 & 8.4 & 13.2 & 8.3 \\
\hline 6 & 12.9 & 12.5 & 13.4 & 8.1 & 10.6 & 8.0 \\
\hline 7 & 13.4 & 12.5 & 13.4 & 8.1 & 12.3 & 8.2 \\
\hline $\bar{r} \pm S . D$. & $13.0 \pm 1.1$ & $13.4 \pm 2.0$ & $13.1 \pm .73$ & $8.1 \pm .30$ & $11.3 \pm 1.1$ & $8.1 \pm 12$ \\
\hline
\end{tabular}
two-year-old open heifers.

\footnotetext{
"CR.0 indicator
}

"Includes $1.4 \mathrm{~kg}$ pellets to heifers; $3.6 \mathrm{~kg}$ pellets to cows. 
animals rather than for groups of animals as illustrated above. In addition, calculation of intake by day is probably less representative of frequently used methods than is calculation based on composite data. Compositing data does, of course, disregard daily fluctuation in intake levels which could be an important factor in intake studies.

Obviously, developing regression equations to adjust $\mathrm{Cr}_{2} \mathrm{O}_{3}$ estimated data is subject to a number of criticisms. If dry lot studies such as that described above are used, time and labor would be greatly increased. In addition, harvested herbage may not be representative of forage consumed under pasture or range conditions. Perhaps the most logical application of adjustment techniques would be the determination of intake on small numbers of animals fitted with fecal collection bags, dosed with $\mathrm{Cr}_{2} \mathrm{O}_{3}$ and grazing under the same conditions as a larger group of animals dosed with $\mathrm{Cr}_{2} \mathrm{O}_{3}$ only. This method requires on to assume that fecal collection techniques provide accurate estimates of intake; a fact which is true, provided digestibility estimates are accurate.

With regard to the use of unadjusted data, investigators sometimes assume that intake estimates obtained by indicator procedures are adequate for comparative purposes even though absolute values cannot be ascertained. Our investigation illustrated that this assumption is not always valid. Estimates of heifer's intakes were nine times more inflated than those of cows indicating that deviations from actual values were different for different rations. The assumption of legitimate relative comparisons would thus be true only for ruminants consuming similar diets. It could not be determined from this study if lactation contributed to divergence of estimates from measured values.

The diurnal excretion pattern of $\mathrm{Cr}_{2} \mathrm{O}_{3}$ (Kane et al. 1952; Putnam et al. 1958) has been much discussed and is considered a major drawback to its use. However, Blaxter et al. (1956) showed that rates of fecal production and expulsion are inconstant and exhibit a diurnal pattern due to a diurnal pattern of feed intake. They concluded that concentrations of inert markers in feces merely reflected these patterns. The problem to be overcome in using indicators such as chromic oxide is to determine the proper sampling time(s) at which concentration of marker in feces is most near its mean level. This, of course, varies with feeds consumed and their rate of passage through the gastro-intestional tract.

Time of fecal sampling in this study may have been nearer mean concentration level in cows than in heifers since more accurate estimates were obtained in the former. Passage rate was probably different in the two groups of cattle since cows received a greater percentage of pellets in their diets. It has been shown (O'Dell et al. 1963) that pelleting of roughages decreases rumen retention time resulting in increased passage rate through the digestive tract.

In conclusion, it was shown that investigators can more accurately estimate roughage intakes by using linear regression equations to predict actual consumption from intake values derived by the $\mathrm{Cr}_{2} \mathrm{O}_{3}$ dilution procedure. Researchers could use this corrective measure to refine the indicator method of estimating intakes under grazing conditions by first determining forage intake from total fecal collections and using these values to develop prediction equations. Meaningful data would need to come from ranges or pastures similar to those from which intakes are being investigated. Likewise, relative comparisons of forage intake may be valid only when ruminants consume the same or similar diets.

\section{Literature Cited}

A.O.A.C. 1965. Official Methods of Analysis (10th ed). Association of Official Agricultural Chemists, Washington, D.C.

Blaxter, K.L., N. McGraham and F.W. Wainman. 1956. Some observations on the digestibility of food by sheep and on related problems. Brit. J. Nutr. 10: 69-91.

Connor, J.M., V.R. Bohman, A.L. Lesperance, and F.E. Kinsinger. 1963. Nutritive evaluation of summer range forage with cattle. J. Anim. Sci. 22:691.

Kane, E.A., W.C. Jacobson, and L.A. Moore. 1952. Diurnal variation in the excretion of chromium oxide and lignin. J. Nutr. 47:263-273.

Kiesling, H.E., H.A. Berry, A.B. Nelson and C.H. Herbel. 1969. Recovery of chromic oxide administered in paper to grazing steers. J. Anim. Sci. 29:361-364.

Kimura, F.T., and V.L. Miller. 1957. Improved determination of chromic oxide in cow feed and feces. J. Agr. Food Chem. 5:216.

O'Dell, G.D., W.A. King, W.C. Cook and S.L. Moore. 1963. Effect of physical state of coastal bermuda grass hay on passage through digestive tract of dairy heifers. J. Dairy Sci. 46:38-42.

Putnam, P.A., J.K. Loosli and R.G. Warner. 1958. Excretion of chromium oxide by dairy cows. J. Dairy Sci. 41:1723-1729.

Tilley, J.J.M. and R.A. Terry, 1963. A two-stage technique for the in vitro digestion of forage crops. J. Brit. Grassld. Soc. 18:104-111.

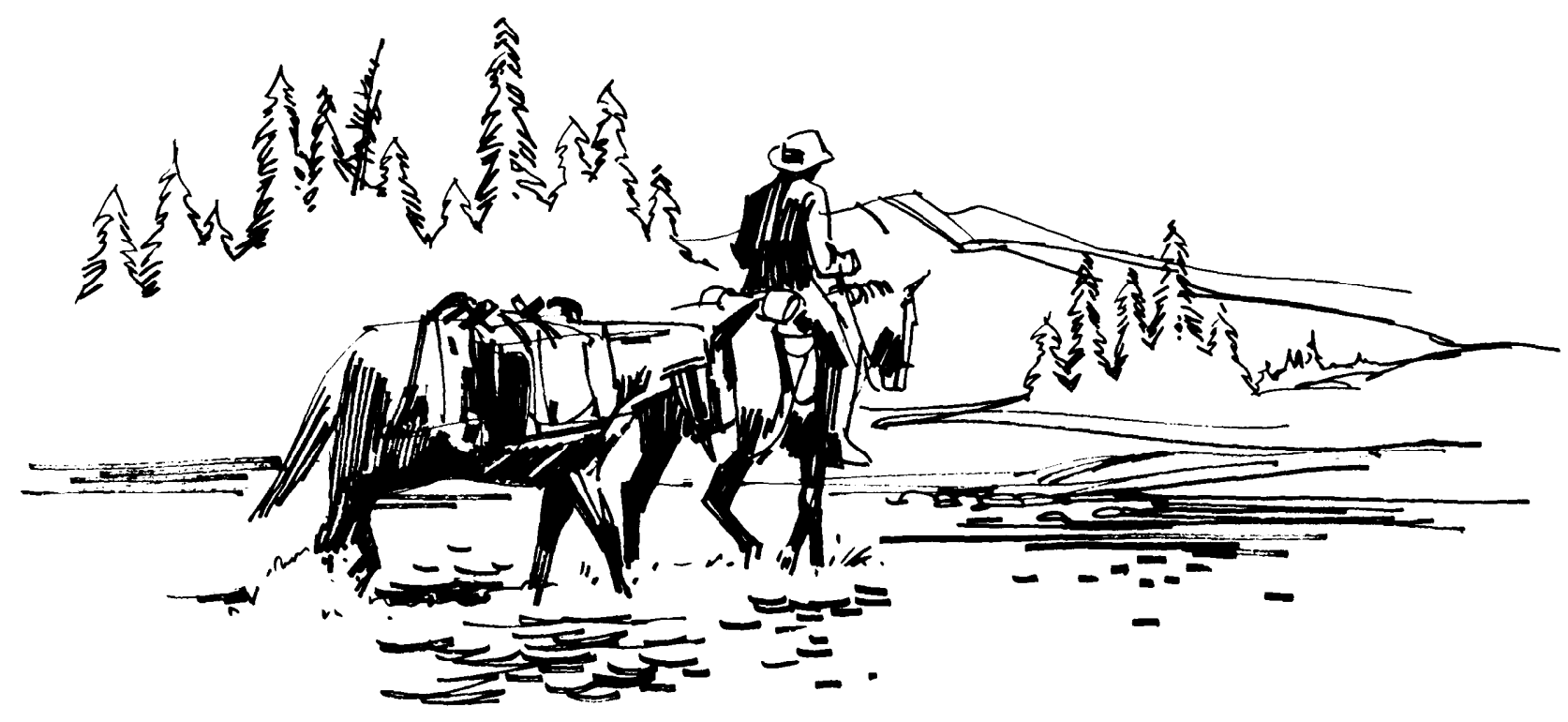

